\title{
Machining performance of aluminium matrix composite and use of WPCA based Taguchi technique for multiple response optimization
}

\author{
Diptikanta Das $^{a *}$, Purna Chandra Mishra ${ }^{a}$, Saranjit Singha ${ }^{a}$ Anil Kumar Chaubey ${ }^{b}$ and Bharat \\ Chandra Routara ${ }^{a}$
}

${ }^{a}$ School of Mechanical Engineering, KIIT University, Bhubaneswar-751024, India ${ }^{b}$ CSIR-Institute of Minerals \& Materials Technology, Bhubaneswar-751013, India

\begin{tabular}{l}
\hline C H R O N I C L E \\
\hline Article history: \\
Received June 182017 \\
Received in Revised Format \\
August 252017 \\
Accepted October 242017 \\
Available online \\
October 242017 \\
\hline Keywords: \\
Aluminium matrix composite \\
Turning \\
Weighted principal component \\
analysis \\
Taguchi
\end{tabular}
A B S T R A C T

\begin{abstract}
Silicon carbide ( $\mathrm{SiC}$ ) particulate impregnated $\mathrm{Al} 7075$ matrix composite was fabricated by stir casting method and then heat treated to T6 condition. It was then machined with multiple layer of TiN coated tungsten carbide (WC) inserts in dry environment and pollution free Spray Impingement Cooling (SIC) environment to compare the machining performance. SIC environment presented better machining performance with respect to cutting tool temperature $(\mathrm{T})$, average roughness of the machined surface $(\mathrm{Ra})$ and tool flank wear (VBc). Quadratic response surface models were developed by computing the experimental data. Weighted Principal Component Analysis (WPCA) based Taguchi technique was adopted to optimize the multiple responses simultaneously, which resulted $40 \mathrm{~m} / \mathrm{min}$ of cutting speed (V), $0.05 \mathrm{~mm} / \mathrm{rev}$ of feed (f) and $0.2 \mathrm{~mm}$ of cutting depth (d) was the optimal combination of process parameters.
\end{abstract}

\section{Introduction}

Aluminium matrix composites (AMCs) impregnated with hard ceramic particulates are replacing the conventional materials in automobile, aerospace, marine and military applications for their significant properties; like high temperature resistance, high stiffness and high strength to weight ratio (Manna \& Bhattacharyya, 2003; Yingfei et al., 2010; Mishra et al., 2015; Das et al., 2015). Existence of hard SiC particulates in the composites causes difficulty in machining with carbide tip tools, leading to inferior surface quality and too much tool wear (Manna \& Bhattacharyya, 2003; Panda et al., 2017). Surface roughness influences the product quality (Ramezani et al., 2015) and tool wear is one of the predominant component of product cost. Davim (2002), during turning of A356/SiC composite with polycrystalline diamond (PCD) inserts, observed average roughness and maximum peak-to-valley height reduced on increasing cutting speed, at a constant feed. Better surface quality was observed while machining $\mathrm{Al} / \mathrm{SiC}$ composite with TiN coated tool than uncoated tool at lower feed and higher cutting speeds (Kilickap et al., 2005). Kannan and Kishawy (2008) reported inferior machined surface quality of A356/SiC composites in wet machining than dry machining, which was due to flush-out of loosely bonded particulates by the coolants; however Ge et al. (2008) observed more deteriorated surface quality during

* Corresponding author

E-mail: diptikantadas@yahoo.co.in (D. Das)

2018 Growing Science Ltd.

doi: $10.5267 /$ j.jiiec.2017.10.001 
dry cutting of $\mathrm{Al} 2024 / \mathrm{SiC}$ composites due to crack and pit formation on the machined surface. Use of coolant during turning increased abrasion between the flank and machined surface, which increased groove wear and deteriorated the surface quality (Ding et al., 2005). Kumar et al. (2014), during dry turning $\mathrm{Al}-\mathrm{Cu}-\mathrm{TiC}$ hybrid composites observed high average surface roughness value at low speed of cutting $(40 \mathrm{~m} / \mathrm{min})$; and it was reduced at higher speed $(120 \mathrm{~m} / \mathrm{min})$ for different fractional combinations of $\mathrm{TiC}$ in the composite. Increase of cutting depth or feed rate also increased average roughness of the machined surface. During turning Al 7075 alloy and Al 7075/SiC (10 wt.\%) MMCs using carbide and PCD inserts, Bhushan et al. (2010) observed that the roughness of machined surface of the alloy was less than that of the AMC; and tool wear was less during turning the alloy as compared to the AMC. PCD inserts suffered less wear than the carbide inserts during machining the AMC. Sahoo et al. (2017), while dry turning Al 63400 alloy, applied WPCA along with response surface methodology to investigate the optimized parameters for machined surface roughness and cutting tool vibration; and reported the combination of $600 \mathrm{rpm}$ (spindle speed), $25 \mathrm{~mm} / \mathrm{min}$ (feed rate) and $0.2 \mathrm{~mm}$ (depth of cut) were the optimal parameters for the quality targets. Sahu et al. (2015), while turning AISI 1015 steel with carbide inserts observed improved cutting performance with respect to surface quality, cutting temperature and rate of material removal in the SIC environment than those with the dry environment. In our previous work (Mishra et al., 2015), use of SIC environment for turning the as cast AMC with uncoated carbide inserts also proved beneficial.

Flank wear is a major form of tool wear that exists due to excessive heat generation as a result of friction between tool flank and machined surface. If cutting depth during turning is less than the tool nose radius, flank wear at nose corner (VBc) becomes predominant (Sahoo \& Pradhan, 2013). Loss of dimensional accuracy, poor surface finish and increased energy consumption are the detrimental effects of flank wear. Flank wear accelerated with increasing the feed, cutting speed or depth of cut; and abrasion was the principal mechanism of flank wear during turning LM6/SiC MMCs with uncoated carbide inserts in dry condition (Manna \& Bhattacharyya, 2003). Ge et al. (2010) observed adhesion on the flank surface and abrasion on the rake surface of PCD tools, while turning Al 2009/SiC composite in kerosene mist environment. Uncoated carbide inserts possessed lesser tool life than that of the TiN coated carbide inserts; and increase of either of the cutting parameters (i.e. speed of cutting, feed or cutting depth) resulted increase of tool wear, during wet turning alumina impregnated AMCs (Bansal \& Upadhyay, 2013). While turning of SiC reinforced AMC in dry condition with uncoated carbide insets, Sahoo \& Pradhan (2013) reported abrasion and adhesion were the principal tool wear mechanisms; and the most significant parameter was cutting speed taken after by feed, for the tool flank wear.

Open literature reveals PCD and TiN coated carbide inserts have the potential to machine the AMCs. For economical viability, tungsten carbide inserts coated with multiple layers of TiN are used in the present experiments for turning the heat treated AMC. Objective of this research is to compare the machining performance of $\mathrm{SiC}$ particulate reinforced heat treated Al 7075 composites during turning in dry environment and pollution free SIC environment; and to implement WPCA based Taguchi technique to identify an optimal combination of machining process parameters for the multiple performance characteristics, i.e. cutting tool temperature $(\mathrm{T})$, average roughness of the machined surface (Ra) and cutting tool flank wear $(\mathrm{VBc})$ during turning. As use of WPCA for multiple response optimization during turning heat treated AMCs in SIC environment is not available in open literature, an attempt has been taken to solve the optimization problem using this method. Moreover, form of the chips produced during turning the AMC in both the cutting environments are also studied.

\section{Materials and Methods}

\subsection{Workpiece}

A1 7075 alloy matrix composite reinforced with 25 wt. \% SiC particulates (of mean particle size 6.18 $\mu \mathrm{m})$ was used as workpiece for the machining experiments. The AMC was processed through liquid metallurgy route or stir casting method. During fabrication, the alloy was melted at $820^{\circ} \mathrm{C}$ in a Jay 
crucible make electrical resistance furnace (3-phase, $440 \mathrm{~V}, 50 \mathrm{~Hz}, 7.5 \mathrm{~kW}$, maximum working temperature $1100^{\circ} \mathrm{C}$ with temperature control accuracy $\pm 10^{\circ} \mathrm{C}$ ) mounted with a speed regulated stirring system and temperature controller. To record the temperature of molten metal a K-type thermocouple was inserted in the crucible. On the surface of the molten alloy vortex was created by stirring at a speed of $160 \mathrm{rpm}$. SiC particulates (preheated to $900^{\circ} \mathrm{C}$ for 2 hours) were then fed into the vortex of molten alloy using a spatula at a feed rate of about $10 \mathrm{~g} / \mathrm{min}$. The stirring was continued for 10 minutes at a speed of $220 \mathrm{rpm}$. The immersion depth of the stirrer was about $2 / 3^{\text {rd }}$ of the slurry (composite) height in the crucible. The composite slurry was degassed with solid hexachloroethane tablet before pouring into a steel mold. After pouring the slurry $\left(\right.$ at $\left.800^{\circ} \mathrm{C}\right)$ into the mold, it was cold to room temperature in steel air. Leco GDS500A Optical Emission Spectrometer (OES) was used for chemical composition test of the $\mathrm{AMC}$ and the result is presented in Table 1.

The cast AMC bar was heat treated to T6 condition using Labotech make BDI 73 muffle furnace (with temperature control accuracy $\pm 3^{0} \mathrm{C}$ ). During heat treatment the composite was solution annealed for 2 hours at $483^{\circ} \mathrm{C}$, followed by water quenching. It was then employed to precipitation hardening for 24 hours at $122^{\circ} \mathrm{C}$, followed by cooling to room temperature in steel air. Uniform dispersion of SiC particles in the matrix alloy was observed by Lieca DMI3000 M inverted optical microscope. The optical micrograph of the AMC sample is shown in Fig. 1. Physical properties (density and \% of porosity) and mechanical properties (hardness, ultimate tensile strength, compressive strength, impact strength and flexural strength) of the heat treated composite were determined and the results are presented in Table 2 . The workpiece for turning was of cylindrical shape with diameter $50 \mathrm{~mm}$ and length $130 \mathrm{~mm}$; however, the machining length for each run was $80 \mathrm{~mm}$.

Table 1

Chemical composition test results of the AMC sample

\begin{tabular}{ccccccccccc}
\hline Element & Silicon & Iron & Copper & Manganese & Magnesium & Zinc & Titanium & Chromium & Aluminium & Others \\
\hline Weight \% & 1.94 & 0.549 & 1.33 & 0.14 & 2.28 & 6.11 & 0.048 & 0.218 & 88.1 & Rest \\
\hline
\end{tabular}

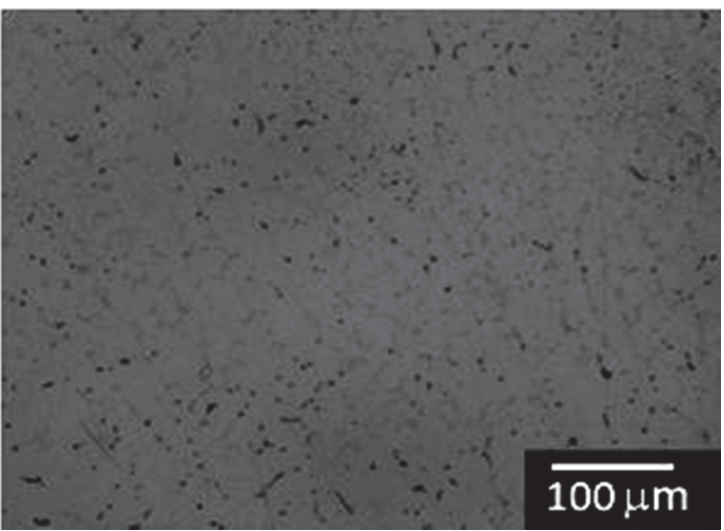

Fig. 1. Optical micrograph of the AMC sample

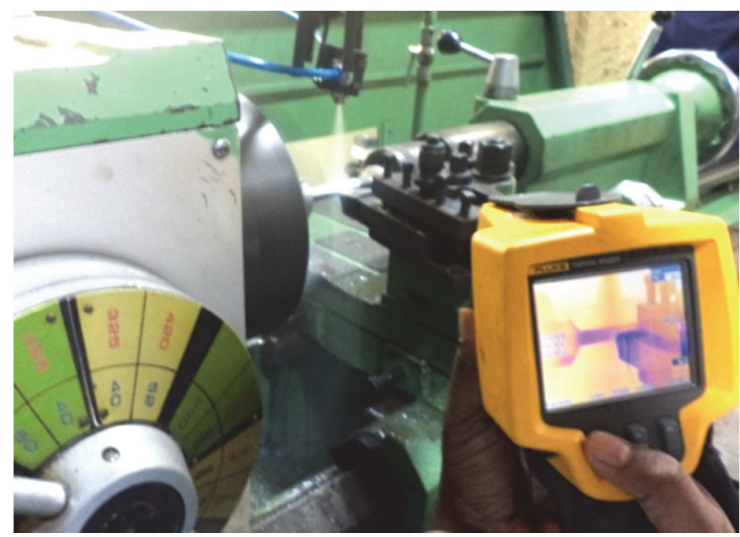

Fig. 2. Experimental setup during turning

Table 2

Properties of the T6 conditioned AMC sample

\begin{tabular}{ccccccc}
\hline $\begin{array}{c}\text { Density } \\
\left(\mathrm{g} / \mathrm{cm}^{3}\right)\end{array}$ & $\begin{array}{c}\text { \% of } \\
\text { porosity }\end{array}$ & $\begin{array}{c}\text { Hardness } \\
(\mathrm{HRB})\end{array}$ & $\begin{array}{c}\text { Ultimate tensile } \\
\text { strength }(\mathrm{MPa})\end{array}$ & $\begin{array}{c}\text { Compressive } \\
\text { strength }(\mathrm{MPa})\end{array}$ & $\begin{array}{c}\text { Impact } \\
\text { strength }\left(\mathrm{kJ} / \mathrm{m}^{2}\right)\end{array}$ & $\begin{array}{c}\text { Flexural } \\
\text { strength }(\mathrm{MPa})\end{array}$ \\
\hline 2.802 & 2.98 & 96.3 & 375.76 & 978.34 & 105.80 & 133 \\
\hline
\end{tabular}




\subsection{Experimentation and measurement}

The AMC workpiece was machined with $\mathrm{TiN}-\mathrm{TiCN}-\mathrm{Al}_{2} \mathrm{O}_{3}-\mathrm{TiN}$ coated WC inserts (of ISO designation CNMG 120408), using a fresh cutting edge for each run. The cutting inserts were mounted rigidly to a right hand turning tool holder of ISO designation PCLNR 2525M12, which provides back rake angle $6^{0}$, clearance angle $5^{0}$, inclination angle $-6^{0}$, major cutting edge angle $95^{\circ}$ and nose radius $0.8 \mathrm{~mm}$. A high speed precision lathe (HMT-NH 22 with maximum spindle speed $2040 \mathrm{rpm}$ and power $11 \mathrm{~kW}$ ) was used for turning in dry environment and SIC environment to compare machining performance of the AMC sample in both the conditions. During turning, the workpiece was supported by a revolving center in the tailstock to prevent the possibility of chatter. Fig. 2 represents the experimental setup during turning the AMC sample in SIC environment. Schematic of the SIC setup developed is shown in Fig. 3. It consists of an air compressor, water pump, pressure regulating valves and a nozzle. The pressure regulating valves allow air and water to flow at desired pressures into the nozzle, where these are mixed and air-water spray is generated. The spray was directed to the cutting tool-workpiece interface at a Nozzle Tip Distance (NTD) of $155 \mathrm{~mm}$, during machining. For these experiments, a mixture of air at 3 bar and water at 3 bar was used for spray generation during turning the AMC in SIC environment. The turning experiments in both dry and SIC environments were designed as per Taguchi $\mathrm{L}_{16}$ standard orthogonal array. Machining process parameters along with their levels used for turning are presented in Table 3.

During turning, the cutting tool temperature $(\mathrm{T})$ at its rake face (close to the grounded surface) was measured using infrared radiation technique by Fluke Ti32 high-definition infrared thermal imager, positioned at a distance of about $200 \mathrm{~mm}$ from the tool rake face, as shown in Fig. 2. Ra was measured using Taylor Hobson-Surtronic 25 surface roughness tester (Fig. 4), with $4 \mathrm{~mm}$ of assessment length and $0.8 \mathrm{~mm}$ of cut-off length. Surface roughness profiles were generated by Taylor Hobson data acquisition software (Taly Gold). VBc was measured by Nikon V10AD profile projector and images of the worn tools were captured by a stereo zoom microscope (Radical Instruments RSM 8). Flank wear measurements were taken at the nose corner of the cutting tools, as depth of cut was less than the tool nose radius during turning. All the measurements followed three point average method for each response $(\mathrm{T}, \mathrm{Ra}$ and $\mathrm{VBc}$ ), i.e. observations were taken for three times and their average was considered as the response value.

Table 3

Machining process parameters along with their levels

\begin{tabular}{ccccc}
\hline \multirow{2}{*}{ Machining process parameters } & \multicolumn{4}{c}{ Levels of parameters } \\
\cline { 2 - 5 } & 1 & 2 & 3 & 4 \\
\hline Cutting speed, V (m/min) & 40 & 106 & 169 & 206 \\
Feed, f $(\mathrm{mm} / \mathrm{rev})$ & 0.05 & 0.1 & 0.16 & 0.2 \\
Depth of cut, d $(\mathrm{mm})$ & 0.2 & 0.3 & 0.4 & 0.5 \\
\hline
\end{tabular}

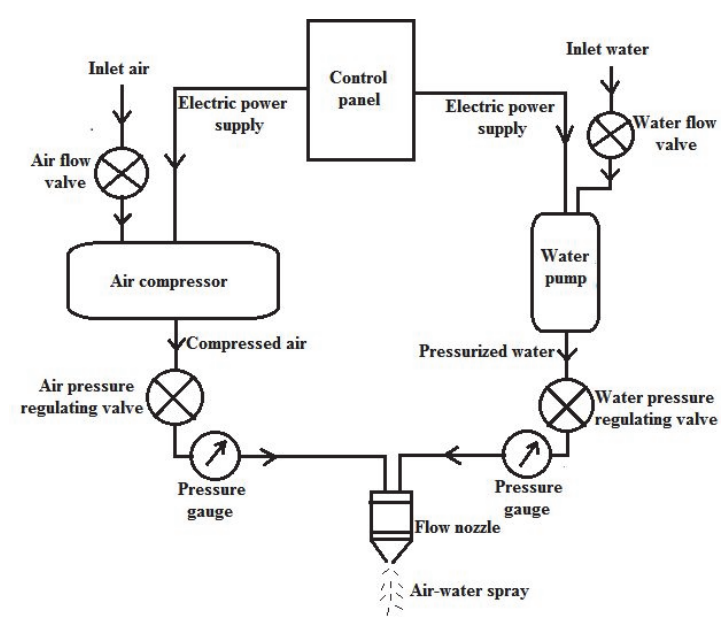

Fig. 3. Schematic of the SIC setup

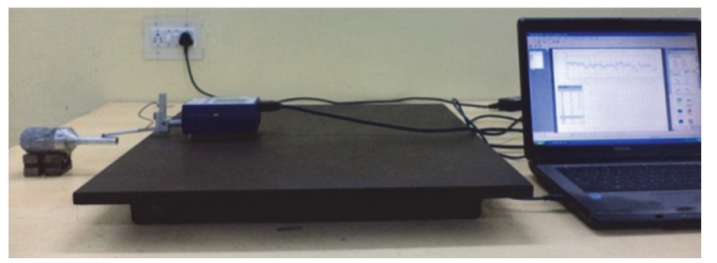

Fig. 4. Measurement of surface roughness 


\section{Results and Discussion}

\subsection{Investigation on machining performance in dry and SIC environments}

Table 4

Experimental results of $\mathrm{T}, \mathrm{Ra}$ and $\mathrm{VBc}$ in dry and SIC machining environments

\begin{tabular}{cccccccccc}
\hline Run No. & \multicolumn{3}{c}{ Levels of process parameters } & \multicolumn{2}{c}{$\mathrm{T}\left({ }^{0} \mathrm{C}\right)$} & \multicolumn{2}{c}{ Ra $(\mu \mathrm{m})$} & \multicolumn{2}{c}{ VBc $(\mathrm{mm})$} \\
\hline & $\mathrm{V}$ & $\mathrm{f}$ & $\mathrm{d}$ & Dry & SIC & Dry & SIC & Dry & SIC \\
\cline { 2 - 10 } 1 & 1 & 1 & 1 & 56.5 & 33.37 & 1.37 & 1.27 & 0.107 & 0.096 \\
2 & 1 & 2 & 2 & 61.53 & 43.93 & 1.63 & 1.95 & 0.123 & 0.118 \\
3 & 1 & 3 & 3 & 75.93 & 47.93 & 2.33 & 2.27 & 0.154 & 0.143 \\
4 & 1 & 4 & 4 & 88.47 & 65.60 & 2.65 & 2.51 & 0.178 & 0.169 \\
5 & 2 & 1 & 2 & 86.9 & 44.87 & 1.57 & 1.17 & 0.149 & 0.143 \\
6 & 2 & 2 & 1 & 83.63 & 50.93 & 1.35 & 1.26 & 0.151 & 0.149 \\
7 & 2 & 3 & 4 & 106.67 & 66.13 & 2.13 & 2.03 & 0.169 & 0.162 \\
8 & 2 & 4 & 3 & 99.43 & 72.87 & 2.17 & 2.19 & 0.18 & 0.173 \\
9 & 3 & 1 & 3 & 106.53 & 52.00 & 1.21 & 0.99 & 0.178 & 0.167 \\
10 & 3 & 2 & 4 & 110.23 & 67.73 & 1.33 & 1.20 & 0.180 & 0.172 \\
11 & 3 & 3 & 1 & 105.45 & 57.07 & 1.99 & 1.40 & 0.188 & 0.182 \\
12 & 3 & 4 & 2 & 107.54 & 70.20 & 2.09 & 2.00 & 0.191 & 0.189 \\
13 & 4 & 1 & 4 & 116.76 & 77.10 & 1.16 & 0.89 & 0.225 & 0.210 \\
14 & 4 & 2 & 3 & 115.78 & 71.47 & 1.24 & 1.19 & 0.229 & 0.223 \\
15 & 4 & 3 & 2 & 107.6 & 69.73 & 1.56 & 1.34 & 0.236 & 0.230 \\
16 & 4 & 4 & 1 & 105.56 & 65.17 & 1.85 & 1.72 & 0.240 & 0.238 \\
\hline
\end{tabular}

The experimental results of $\mathrm{T}, \mathrm{Ra}$ and $\mathrm{VBc}$ are presented in Table 4, for both dry and SIC machining environments. Lower values of cutting tool temperatures were observed during machining in SIC condition. The temperature was maximum $\left(116.76^{\circ} \mathrm{C}\right)$ for run no. 13 in dry turning, i.e. with $206 \mathrm{~m} / \mathrm{min}$ of cutting speed, $0.05 \mathrm{~mm} / \mathrm{rev}$ of feed and $0.5 \mathrm{~mm}$ of cutting depth. But for SIC it was reduced by $34 \%$ (i.e. $77.1^{\circ} \mathrm{C}$ ) while machining with the same parameters. The cause of this temperature reduction is dissipation of heat (generated due to friction) to the low temperature air-water mixture by convection. Some of the infrared thermal images are shown in Figs. 5 (a-d) and Figs. 6 (a-d) during turning the AMC in dry environment and SIC environment, respectively, as illustration.

Average roughness of the machined surfaces also reduced while machining in SIC environment. It may be due to the fact that the water particles were finely atomized in presence of compressed air while passing through the nozzle. It reduced the problem of flushing out of the loosely bonded particles from the turned surface of the AMC, which is a common problem in wet machining (Kannan \& Kishawy, 2008). Higher values of average surface roughness were observed at low cutting speeds. It was due to stable Built-Up-Edge (BUE) formation at the lower values of cutting speed. During machining the AMCs, surface quality is affected adversely with the formation of BUE. Unacceptable values of Ra were observed in some of the runs due to formation of these BUEs. It can also be observed from Table 4 (for run nos. 13, 14, 15 and 16) that superior surface finish was achieved at higher values cutting speeds. This enables the machining became more easier due to the stability of the machining system. Low values of $\mathrm{Ra}$ at higher cutting speeds made high speed machining of the composite possible. The surface roughness profiles of the AMC sample in dry and SIC machining environments are presented in Fig. 7 (a-d) and Fig. 8 (a-d) respectively. Optical micrographs of the machined surface (Fig. 9 a-b) reveal that the surface imperfections were due to formation of grooves, particle pull out and particle fracture.

From Table 4, lower values of flank wear are observed during machining the composite in SIC environment than those in dry environment, which may be due to the reduced temperature in the cutting tool-workpiece interface. It may be noted that the values of flank wear are within the limiting criterion of $0.3 \mathrm{~mm}$ (ISO 3685:1993) for all the runs, even at higher parametric range. This may be due to the 
formation of thin stable BUE on the tool tip which protected the cutting edge from rapid wear. Fig. 10 (a-b) shows the images of some worn cutting edges, as illustration. It could be observed from the experimental results corresponding to the runs 13,14, 15 and 16 that as the cutting speed increased, there was a rapid increase of flank wear. It might be due to the absence of BUE at higher machining parameters. The reduced temperature in SIC environment at higher parametric conditions helped in reducing the adhesion; and therefore the formation of BUE is eliminated. The deep scratch marks on the flank face of the tool confirms the abrasive action of the hard SiC particulates. At the same time neither crater wear nor diffusive wear and oxidation observed in the tool, which may be due to low toughness, low plasticity and low melting point of the AMC. However, on the tool face adhesion wear observed; and it might be because of $\mathrm{Al}$ is an active metal (Yanming \& Zehua, 2000). Abrasion and adhesion were the principal flank were mechanisms for the multiple layer of TiN coated carbide inserts during turning. From the visual inspection, the chips formed in dry cutting environment (Fig. $11 \mathrm{a}-\mathrm{b}$ ) are of saw-toothed, semi continuous, tubular and spiral shaped with large curling circle radius, which deteriorated the quality of machined surfaces. Due to high shear stress, cracks are initiated at outer surface of the workpiece forming small voids. As a result of coalescence of these voids, the cracks are propagated forming saw-tooth appearance of the chips. Dual actions of thermoplastic instability and plastic instability may be one more cause of saw-tooth chip formation (Yang \& Li, 2010). Semi continuous chip forms are due to reduced ductility of the composite material for $\mathrm{SiC}$ reinforcement.

In SIC environment, the chips (Figs. $11 \mathrm{c}$-d) are short, thin flaked, segmented and C-shaped with small curling circle radius, which are desirable for reduced roughness on the machined surface. The short and C-shaped chips with small curling circle radius in SIC condition may be due to the pressure of air-water spray, which prevented their further growth. One more cause of the short chips formation in SIC environment may be attributed to brittleness of the composite workpiece due to air-water spray on the hot surface. The average cutting zone temperature considerably reduced as machining was carried out using air-water spray. The work-tool interface zone was little affected by the chips in SIC machining, as they were broken periodically and formed serrated type segmented chips.

From the above discussions, machining of the composite in SIC environment is found more beneficial than dry environment with respect to cutting tool temperature, surface roughness and tool flank wear; and therefore for further investigations, machining of the AMC only in SIC environment is focused.

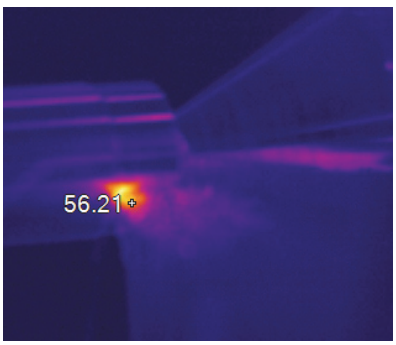

(a)

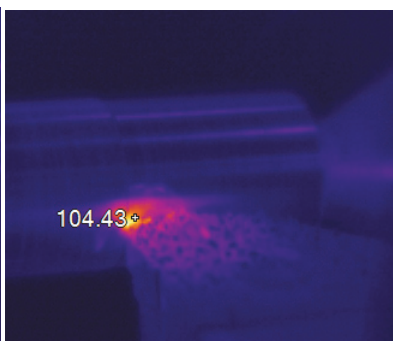

(b)

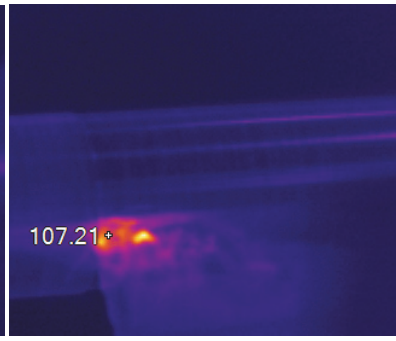

(c)

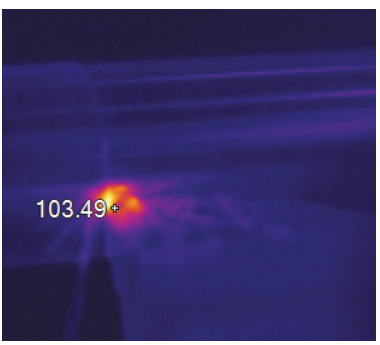

(d)

Fig. 5. Infrared thermal images during turning in dry environment at (a) Run 1; (b) Run 7; (c) Run 11; and (d) Run 16

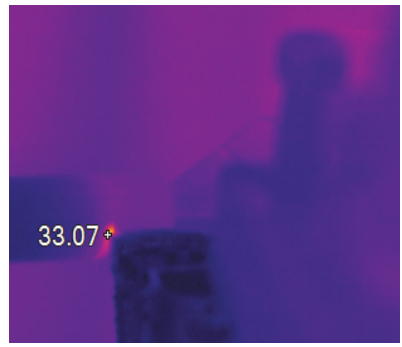

(a)

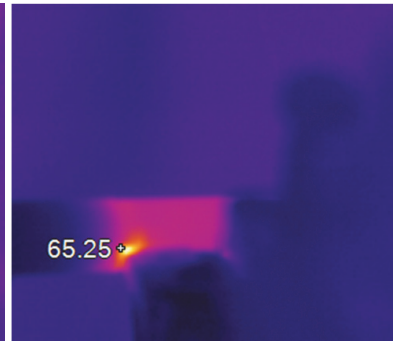

(b)

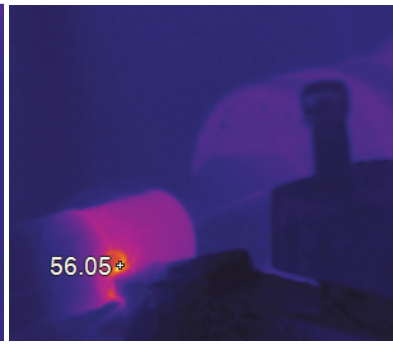

(c)

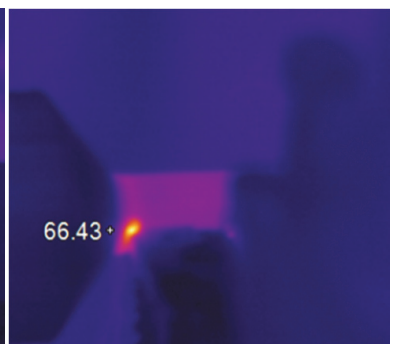

(d)

Fig. 6. Infrared thermal images during turning in SIC environment at (a) Run 1; (b) Run 7; (c) Run 11; and (d) Run 16 


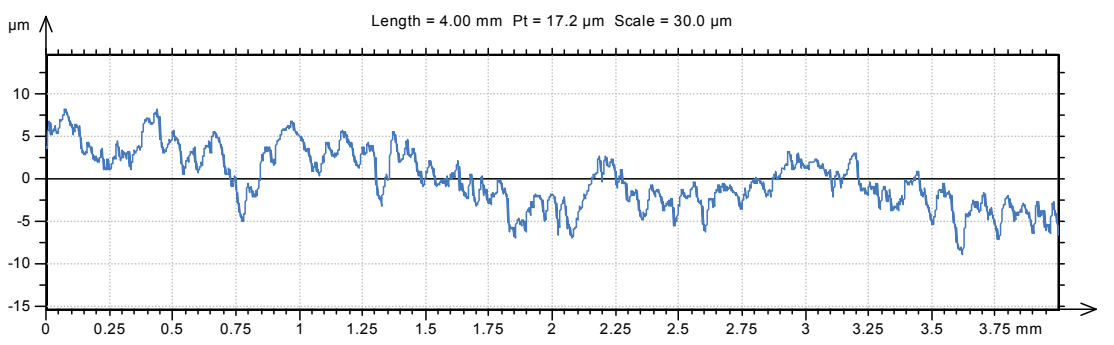

(a)

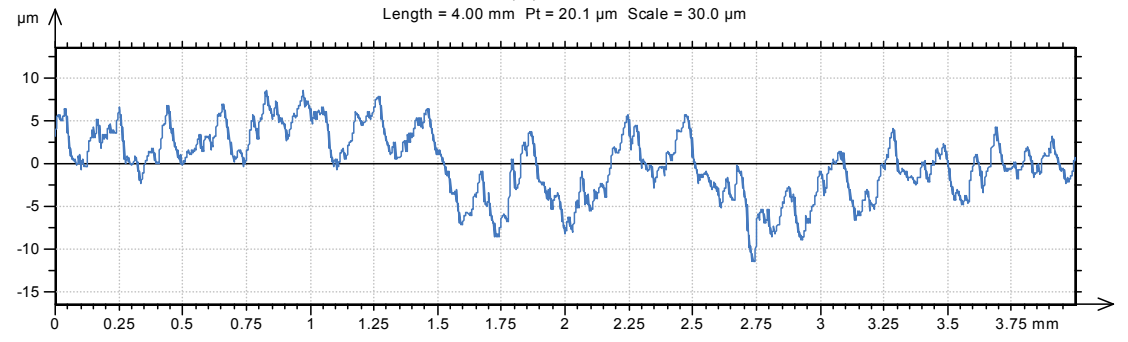

(b)

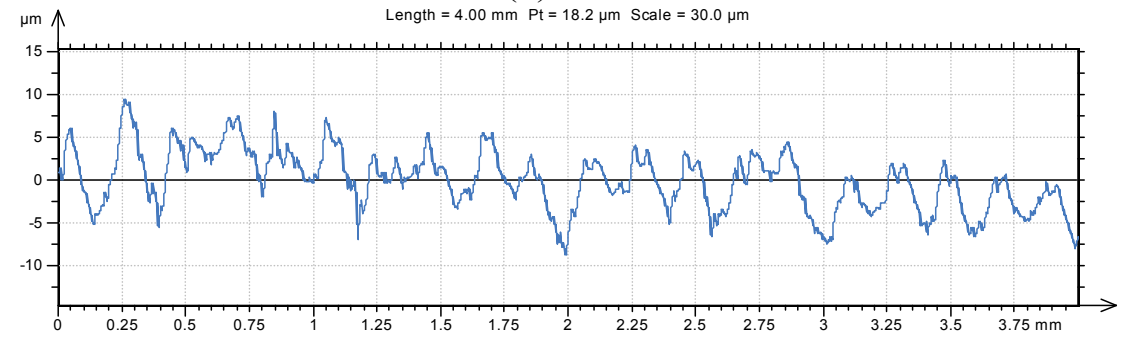

(c)

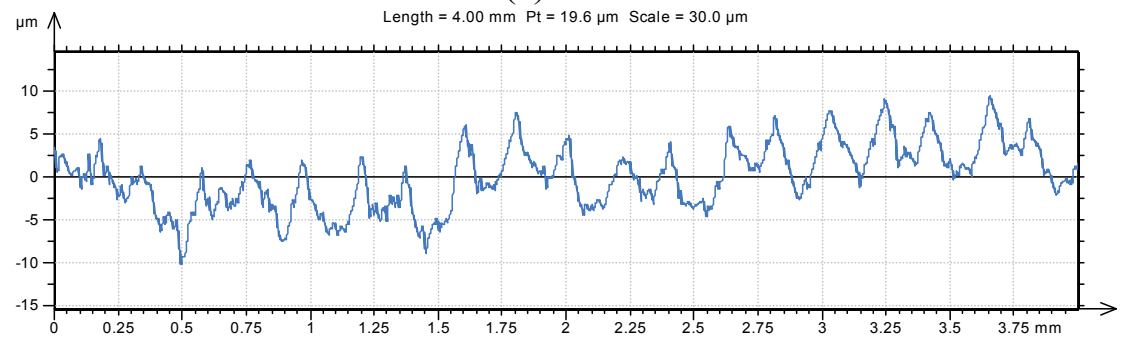

(d)

Fig. 7. Surface roughness profiles after turning in dry environment at (a) Run 1; (b) Run 7; (c) Run 11; and (d) Run 16

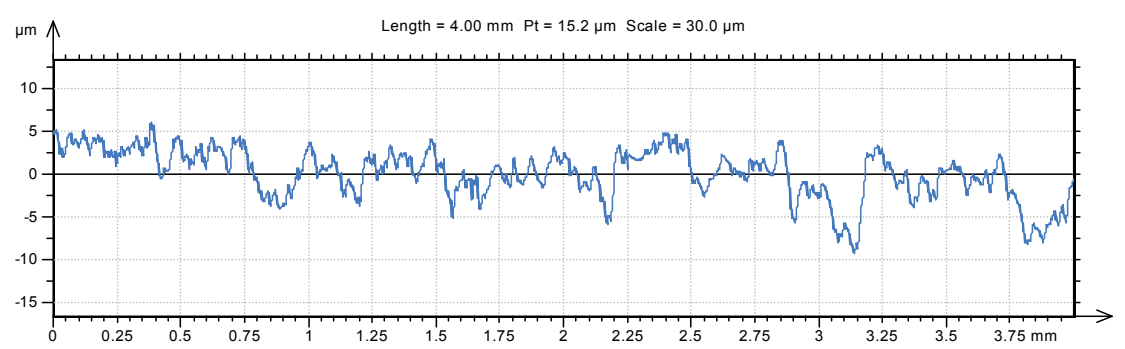

(a) 


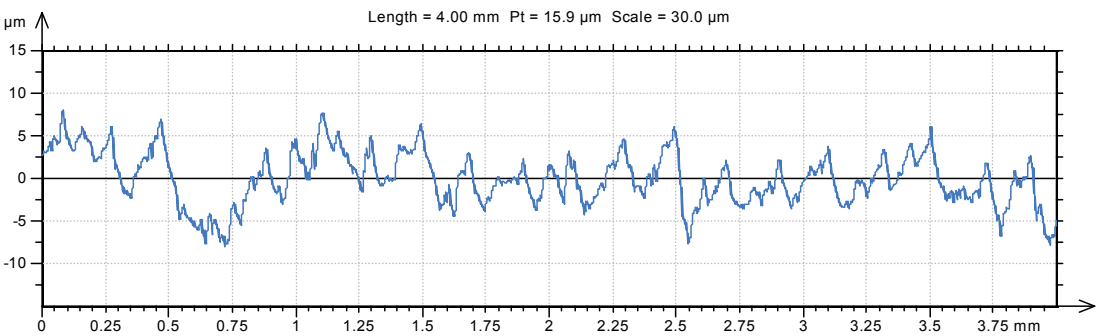

(b)

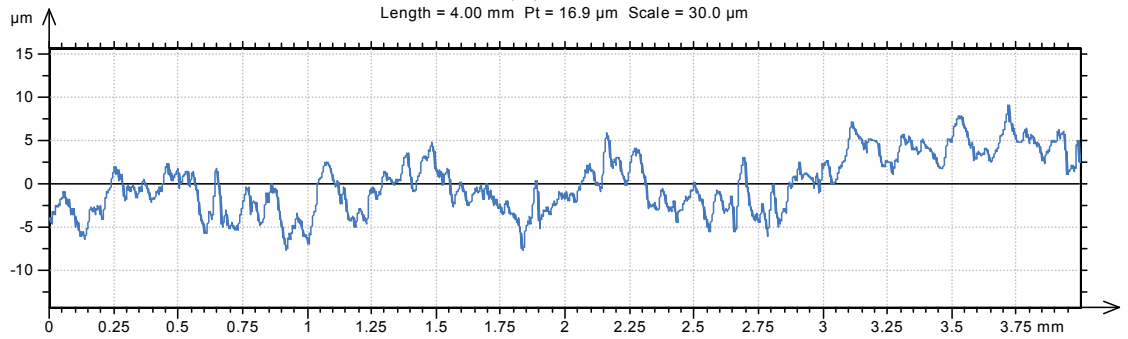

(c)

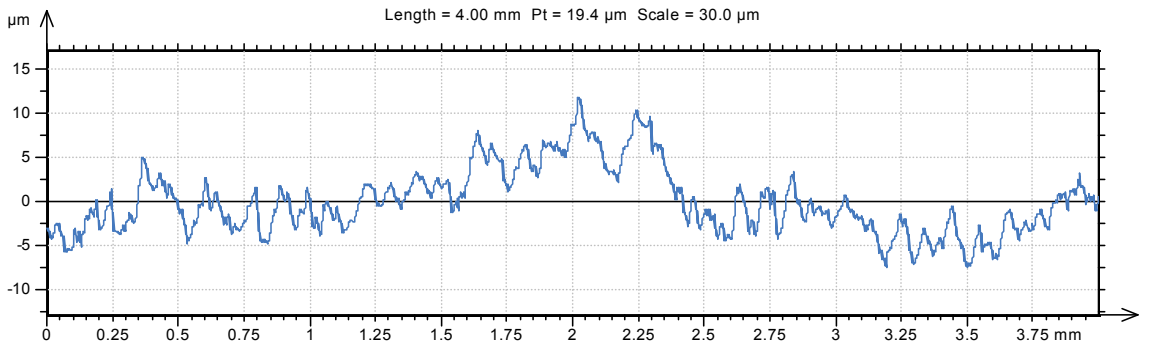

(d)

Fig. 8. Surface roughness profiles after turning in SIC environment at (a) Run 1; (b) Run 7; (c) Run 11; and (d) Run 16

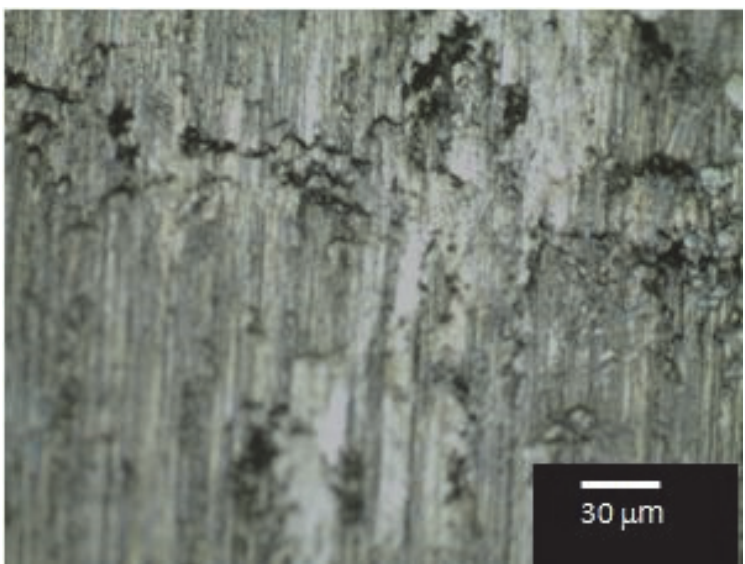

(a)

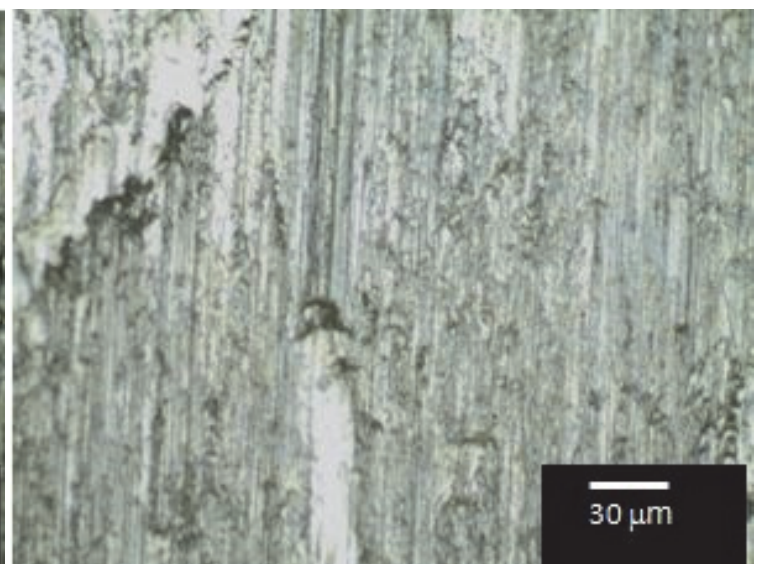

(b)

Fig. 9. Optical micrographs of machined surface after turning at $V=206 \mathrm{~m} / \mathrm{min}, \mathrm{f}=0.2 \mathrm{~mm} / \mathrm{rev}, \mathrm{d}=0.2$ $\mathrm{mm}$ in (a) dry environment; and (b) SIC environment 


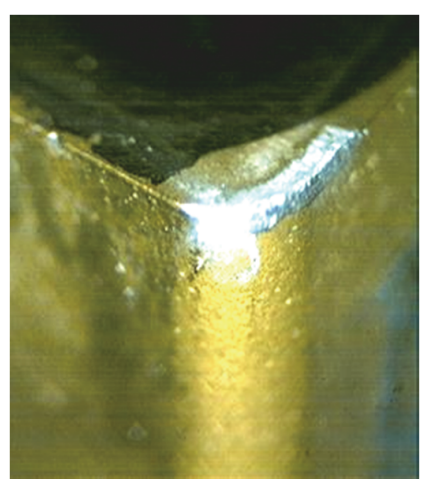

(a)

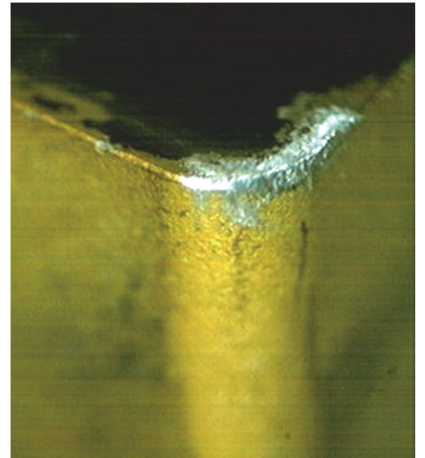

(b)

Fig. 10. Worn cutting edges at $V=206 \mathrm{~m} / \mathrm{min}, \mathrm{f}=0.05 \mathrm{~mm} / \mathrm{rev}$ and $\mathrm{d}=0.5 \mathrm{~mm}$ during turning in (a) dry environment; (b) SIC environment

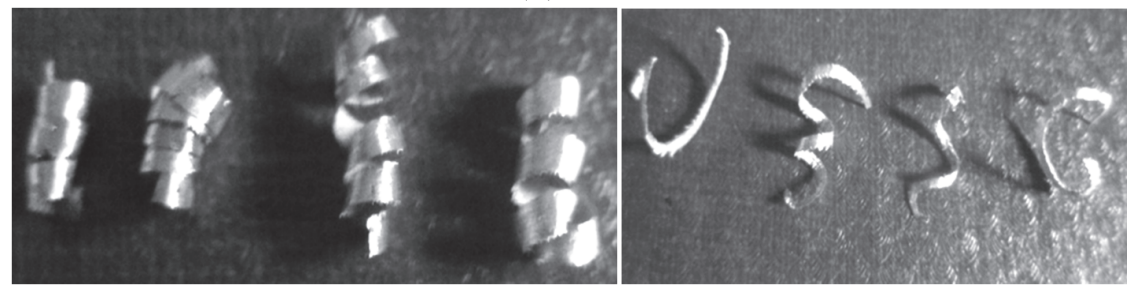

(a)

(b)

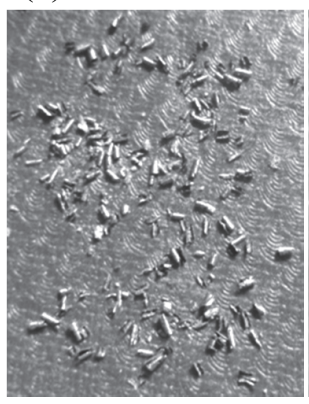

(c)

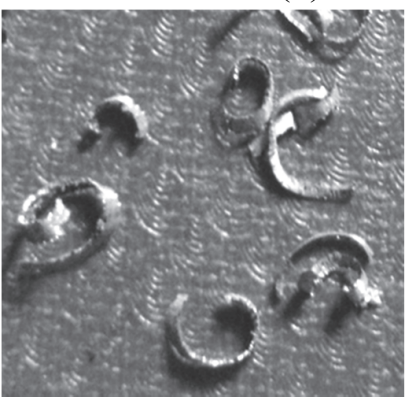

(d)

Fig. 11. Chip forms during turning the AMC at (a) Run 1 in dry environment; (b) Run 15 in dry environment; (c) Run 1 in SIC environment; and (d) Run 15 in SIC environment

\subsection{Influence of machining process parameters during turning in SIC environment}

Main effects plot for T (Fig. 12a) depicts increase of cutting tool temperature with the increase in any of the machining process parameters, i.e. cutting speed, feed or depth of cut. It was due to the increased friction and more heat generation at the work-tool interface zone during turning at higher levels of parameters. The mean temperature increased from $47.71^{\circ} \mathrm{C}$ to $70.87^{\circ} \mathrm{C}$ (around $49 \%$ ), as the speed increased from $40 \mathrm{~m} / \mathrm{min}$ to $206 \mathrm{~m} / \mathrm{min}$. From the main effects plot for Ra (Fig. 12b), it is evident that the average surface roughness reduced on increasing cutting speed. At higher levels of cutting speed the contact area at the tool-chip interface reduces and thus friction reduces. It is one of the cause of better surface finish at higher speeds. Also, formation of built up edge becomes less at higher speed, which may be one more cause of the reduced surface roughness. Higher values of surface roughness are observed with increasing feed, because at higher feed more thrust force is induced (Kumar et al., 2014), which leads to vibration in the workpiece and generation of more heat at the machining zone. Average roughness of the machined surface also increased on increasing the cutting depth, because of the fracture of more $\mathrm{SiC}$ particulates and void formation at higher depth of cut. Similarly, the main effects plot for VBc (Fig. 12c) depicts increase of flank wear with increase of either of machining parameters, which was due to increased cutting force components, friction and heat generation at higher levels of machining parameters. The mean flank wear increased from $0.1315 \mathrm{~mm}$ to $0.2253 \mathrm{~mm}$ (around $71 \%$ ), as the cutting speed increased from $40 \mathrm{~m} / \mathrm{min}$ to $206 \mathrm{~m} / \mathrm{min}$. 


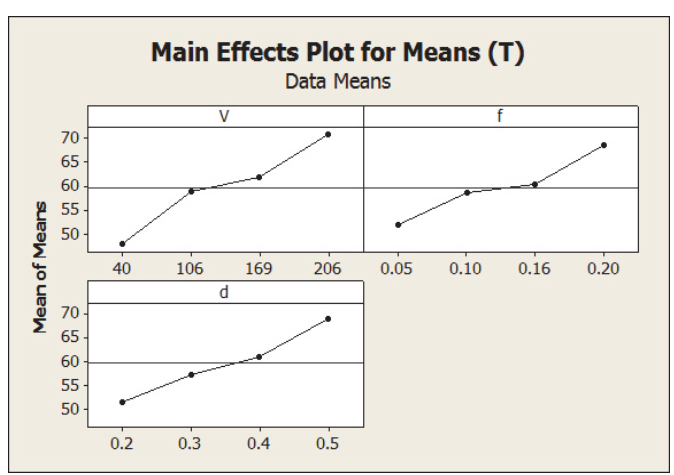

(a)

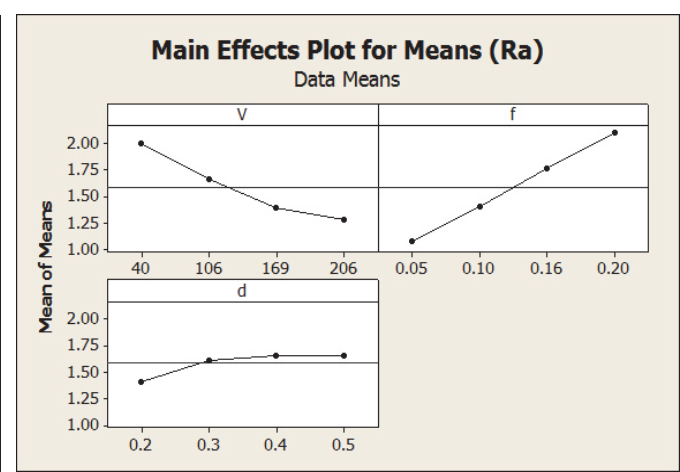

(b)

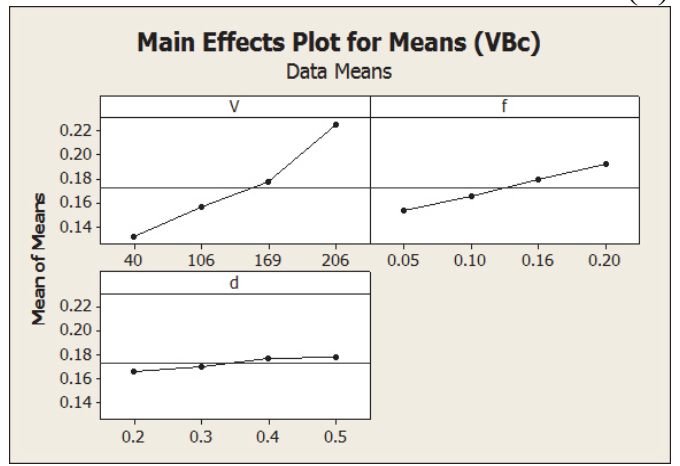

(c)

Fig. 12. Main effects plots for (a) T; (b) Ra; (c) VBc.

\subsection{Response surface models during turning in SIC environment}

Response surface quadratic (second-order) models are generated for better predictability of $\mathrm{T}$, Ra and $\mathrm{VBc}$, considering $\mathrm{V}, \mathrm{f}$ and $\mathrm{d}$ as process variables during turning the $\mathrm{T} 6$ conditioned AMC in SIC environment. These models are generated using the relevant experimental data from Table 4 and by computing the values of various parameters using MINITAB software. Eqs. (1)-(3) represent the secondorder response surface models for $\mathrm{T}, \mathrm{Ra}$ and $\mathrm{VBc}$. The coefficients of determination $\left(\mathrm{R}^{2}\right)$ are close to $100 \%$ and the predicted values of $R^{2}$ are in reasonable agreement with the adjusted $R^{2}$ for all the models, which indicate good prediction of the responses and adequacy of the models (Sahoo et al., 2013; Sahoo et al., 2015).

$$
\begin{aligned}
& T=55.944+12.832 V+13.308 f+4.107 d+0.717 V^{2}+1.776 f^{2}+1.456 d^{2}- \\
& 5.451 V^{*} f+8.892 V * d+3.414 f^{*} d \\
& R^{2}=95.74 \%, R^{2}(a d j)=89.36 \% \\
& R_{a}=1.623-0.443 V+0.484 f+0.168 d+0.036 V^{2}+0.05 f^{2}-0.116 d^{2}+ \\
& 0.07 V * f-0.02 V^{*} d-0.133 f^{*} d \\
& R^{2}=98.45 \%, R^{2}(a d j)=96.12 \% \\
& V_{B c}=0.155+0.049 V+0.013 f+0.000075 d+0.021 V^{2}+0.0016 f^{2}-0.001 d^{2}- \\
& 0.011 V^{*} f-0.0105 V^{*} d+0.009 f^{*} d \\
& R^{2}=97.08 \%, R^{2}(a d j)=92.69 \%
\end{aligned}
$$

\subsection{Weighted principal component analysis (WPCA)}

All the responses considered in this research (i.e. T, Ra and VBc) have their individual influence on the product quality and economy in machining. It is therefore essential to optimize the above responses simultaneously to maintain a good balance between the product quality and machining economy. Since traditional Taguchi method is not sufficient to solve the multiple response optimization problems (Routara et al., 2010), WPCA based Taguchi technique has been used in this study to solve the problem. 
The experimental results during machining the AMC in SIC environment (Table 4) are normalized (between 0 and 1) considering "smaller is better" criterion using eq. (4); and the normalized data are presented in Table 5.

$$
X_{i}^{*}(p)=\frac{\min X_{i}^{o}(p)}{X_{i}^{o}(p)}
$$

where $X_{i}^{*}(p)$ is the normalized data sequence and $X_{i}^{o}(p)$ is the original data sequence of the $i^{\text {th }}$ run and $p^{\text {th }}$ quality characteristic. After normalization of data, correlation of the responses are checked. The Pearson's correlation coefficients (PCC) between the responses are presented in Table 6. As none of the correlation coefficient has zero value, it indicates that all the responses are correlated to each other. Principal Component Analysis (PCA) is then adopted to de-correlate the responses. Table 7 presents the results of PCA, i.e. Eigen value, Eigen vector, accountability proportion (AP) and cumulative accountability proportion (CAP). Then, the individual principal components $\left(Z_{1}, Z_{2}\right.$ and $\left.Z_{3}\right)$ are calculated and presented in Table 8. These are the uncorrelated quality indices of the responses. Next, the Multi-response Performance Indexes (MPI) are evaluated using eq. (5); and these are presented in Table 8 .

$$
M P I=\sum_{k=1}^{p} W_{k} Z_{k}
$$

where $W_{k}$ is the priority weight of $k^{\text {th }}$ principal component, which is equivalent to $A P_{k}$, i.e. accountability proportion of $k^{\text {th }}$ principal component (Routara et al., 2010).

The absolute difference between ideal MPI and its individual value is termed as Combined Quality Loss (CQL); and is treated as single objective function for the multiple response optimization problems. The CQL values and their SN ratios (considering "smaller is better" criterion) are calculated and provided in Table 8. Response table for SN ratios of CQL (Table 9) was computed using Taguchi method to predict optimal combination of machining process parameters for the multiple responses. As the highest values of SN ratios represent the optimal combination of parameters, from Table 9 it is evident that the optimal parametric combination for the multiple quality characteristics is $V_{1}-f_{1}-d_{1}$, i.e. cutting speed of $40 \mathrm{~m} / \mathrm{min}$, feed of $0.05 \mathrm{~mm} / \mathrm{rev}$ and depth of cut of $0.2 \mathrm{~mm}$. Finally, the machining performance for optimal process parameters was verified through some confirmatory experiments with initial and optimal parameter settings. Results of confirmatory experiments (Table 10) shows improvement of quality targets, reasonable agreement between the predicted and experimental values of SN ratios of CQL and the improvement in the SN ratio is $9.6797 \mathrm{~dB}$. These show the feasibility of the WPCA.

Table 5

Normalized data of experimental results in SIC environment

\begin{tabular}{cccc}
\hline Run No. & \multicolumn{3}{c}{ Normalized data } \\
\cline { 2 - 4 } Ideal & 1.0000 & Ra & VBc \\
\hline 1 & 1.0000 & 1.0000 & 1.0000 \\
\hline 2 & 0.7596 & 0.7008 & 1.0000 \\
3 & 0.6962 & 0.4564 & 0.8136 \\
4 & 0.5087 & 0.3921 & 0.6713 \\
5 & 0.7437 & 0.3546 & 0.5680 \\
6 & 0.6552 & 0.7607 & 0.6713 \\
7 & 0.5046 & 0.7063 & 0.5443 \\
8 & 0.4579 & 0.4384 & 0.5549 \\
9 & 0.6417 & 0.4064 & 0.5749 \\
10 & 0.4927 & 0.8990 & 0.5581 \\
11 & 0.5847 & 0.7417 & 0.5275 \\
12 & 0.4754 & 0.6357 & 0.5079 \\
13 & 0.4328 & 0.4450 & 0.4571 \\
15 & 0.4669 & 1.0000 & 0.4305 \\
16 & 0.4786 & 0.7479 & 0.4174 \\
\hline
\end{tabular}


Table 6

PCC between the responses

\begin{tabular}{cccc}
\hline Sl. No. & Correlation between & PCC & Remark \\
\hline 1 & $\mathrm{~T}$ and $\mathrm{Ra}$ & 0.289 & Correlated \\
2 & $\mathrm{~T}$ and VBc & 0.941 & Correlated \\
3 & $\mathrm{Ra}$ and VBc & 0.170 & Correlated \\
\hline
\end{tabular}

Table 7

Results of PCA

\begin{tabular}{cccc}
\hline & $\Psi_{1}$ & $\Psi_{2}$ & $\Psi_{3}$ \\
\hline Eigen value & 2.0427 & 0.9067 & 0.0506 \\
\hline \multirow{2}{*}{ Eigen vector } & 0.684 & -0.144 & -0.715 \\
& 0.298 & 0.95 & 0.094 \\
AP & 0.666 & -0.277 & 0.692 \\
\hline CAP & 0.681 & 0.302 & 0.017 \\
\hline
\end{tabular}

Table 8

Individual principal components, Multi-response performance index and Combined quality loss

\begin{tabular}{ccccccc}
\hline Run No. & $\mathrm{Z}_{1}$ & $\mathrm{Z}_{2}$ & $\mathrm{Z}_{3}$ & MPI & CQL & SN ratio of CQL \\
\hline Ideal & 1.6480 & 0.5290 & 0.0710 & 1.2833 & 0.0000 & $* * * *$ \\
\hline 1 & 1.5588 & 0.2447 & 0.0429 & 1.1362 & 0.1471 & 16.6483 \\
2 & 1.1974 & 0.0988 & 0.0628 & 0.8464 & 0.4369 & 5.1916 \\
4 & 1.0402 & 0.0863 & 0.0036 & 0.7345 & 0.5488 & 3.3039 \\
5 & 0.8319 & 0.1063 & 0.0627 & 0.5997 & 0.6836 & 9.1630 \\
6 & 1.1825 & 0.4296 & 0.0043 & 0.9351 & 0.3482 & 7.5034 \\
7 & 1.0878 & 0.3982 & 0.0438 & 0.8618 & 0.4215 & 3.9486 \\
8 & 0.8705 & 0.1797 & 0.0905 & 0.6486 & 0.6347 & 3.2993 \\
9 & 0.8039 & 0.1664 & 0.0948 & 0.5993 & 0.6840 & 8.9006 \\
10 & 1.0897 & 0.6024 & 0.0235 & 0.9244 & 0.3589 & 5.9562 \\
11 & 0.9297 & 0.4790 & 0.1037 & 0.7796 & 0.5037 & 5.5187 \\
13 & 0.9407 & 0.3736 & 0.0067 & 0.7536 & 0.5297 & 3.4039 \\
14 & 0.7960 & 0.2136 & 0.0534 & 0.6075 & 0.6758 & 7.1335 \\
16 & 0.8985 & 0.7610 & 0.1009 & 0.8434 & 0.4399 & 5.0371 \\
\end{tabular}

Table 9

Response Table for SN ratios of CQL

\begin{tabular}{cccc}
\hline Level & V & f & d \\
\hline 1 & 8.089 & 10.461 & 8.303 \\
2 & 5.979 & 6.422 & 6.044 \\
3 & 5.945 & 4.774 & 5.612 \\
4 & 5.033 & 3.388 & 5.086 \\
\hline Delta & 3.056 & 7.074 & 3.218 \\
\hline Rank & 3 & 1 & 2 \\
\hline
\end{tabular}

Table 10

Results of confirmatory experiments

\begin{tabular}{|c|c|c|c|}
\hline \multirow{3}{*}{ Level } & \multirow{2}{*}{ Initial process parameters } & \multicolumn{2}{|c|}{ Optimal process parameters } \\
\hline & & Prediction & Experiment \\
\hline & $V_{2}-f_{2}-d_{2}$ & $V_{1}-f_{1}-d_{1}$ & $\mathrm{~V}_{1}-\mathrm{f}_{1}-\mathrm{d}_{1}$ \\
\hline $\mathrm{T}$ & 47.62 & & 33.37 \\
\hline $\mathrm{Ra}$ & 1.52 & & 1.27 \\
\hline $\mathrm{VBc}$ & 0.141 & & 0.096 \\
\hline CQL & 0.4483 & & 0.1471 \\
\hline $\mathrm{SN}$ ratio of $\mathrm{CQL}$ & $6.9686 \mathrm{~dB}$ & $14.3309 \mathrm{~dB}$ & $16.6483 \mathrm{~dB}$ \\
\hline
\end{tabular}




\subsection{Analysis of Variance (ANOVA) for CQL}

Statistical ANOVA was conducted at $95 \%$ confidence level to investigate the significance of the machining process parameters and their \% of contribution for CQL. The results (Table 11) indicate that feed was the most significant process parameter (with contribution of $80.53 \%$ ) taken after by depth of cut (with contribution of $10.12 \%$ ) and cutting speed (with contribution of $7.58 \%$ ) for the CQL of multiple performance characteristics under consideration.

Table 11

Results of ANOVA for CQL

\begin{tabular}{cccccc}
\hline Source & Degrees of freedom & Sum of squares & Mean square & Fisher's constant & Probability of significance \\
\hline V & 3 & 0.025671 & 0.008557 & 8.6 & 0.014 \\
f & 3 & 0.272723 & 0.090908 & 91.37 & 0.000 \\
d & 3 & 0.034283 & 0.011428 & 11.49 & 0.007 \\
Error & 6 & 0.00597 & 0.000995 & & 10.12 \\
\hline Total & 15 & 0.338647 & & & 1.76 \\
\hline
\end{tabular}

\section{Conclusions}

- The machining performance of the heat treated Al 7075/25 wt.\% SiC AMC was better in SIC environment as compared to the dry cutting environment, in terms of $\mathrm{T}$, Ra and $\mathrm{VBc}$.

- T and VBc increased with increase in any of the machining process parameters (i.e. V, f or d). Ra reduced with increase in speed, but it increased with increase of either feed or depth of cut. Formation of grooves, particle pull out and particle fracture were the causes of surface imperfections. Abrasion and adhesion were the principal mechanisms of cutting tool wear.

- Saw-toothed, semi continuous, tubular and spiral shaped chips with large curling circle radius were formed during turning the AMC in dry environment, whereas in SIC environment the chips were short, thin flaked, segmented and $\mathrm{C}$-shaped with small curling circle radius.

- Second-order response surface models were generated for T, Ra and VBc. High determination coefficients (close to $100 \%$ ) and reasonable agreement between their predicted and adjusted values indicated good prediction of the responses and adequacy of the models.

- WPCA revealed that during turning the AMC in SIC environment, a combination of $\mathrm{V}, \mathrm{f}$ and $\mathrm{d}$ of $40 \mathrm{~m} / \mathrm{min}, 0.05 \mathrm{~mm} / \mathrm{rev}$ and $0.2 \mathrm{~mm}$, respectively, was the optimal combination of machining parameters for the multiple performance characteristics. From confirmatory experiments, the improvement in SN ratio of CQL was observed to be $9.6797 \mathrm{~dB}$. ANOVA results for CQL indicated that feed was the most significant machining process parameter (with contribution of $80.53 \%$ ) taken after by depth of cut (with contribution of $10.12 \%$ ) and cutting speed (with contribution of $7.58 \%$ ).

\section{References}

Bansal, P., \& Upadhyay, L. (2013). Experimental investigations to study tool wear during turning of alumina reinforced aluminium composite. Procedia Engineering, 51, 818-827.

Bhushan, R. K., Kumar, S., \& Das, S. (2010). Effect of machining parameters on surface roughness and tool wear for $7075 \mathrm{Al}$ alloy $\mathrm{SiC}$ composite. The International Journal of Advanced Manufacturing Technology, 50(5), 459-469.

Davim, J. P. (2002). Diamond tool performance in machining metal-matrix composites. Journal of Materials Processing Technology, 128(1), 100-105.

Ding, X., Liew, W. Y. H., \& Liu, X. D. (2005). Evaluation of machining performance of MMC with PCBN and PCD tools. Wear, 259(7), 1225-1234.

Ge, Y. F., Xu, J. H., Yang, H., Luo, S. B., \& Fu, Y. C. (2008). Workpiece surface quality when ultraprecision turning of $\mathrm{SiC}$ p/Al composites. Journal of materials processing technology, 203(1), 166175. 
Kannan, S., \& Kishawy, H. A. (2008). Tribological aspects of machining aluminium metal matrix composites. Journal of Materials Processing Technology, 198(1), 399-406.

Kanta Das, D., Mishra, P. C., Singh, S., \& Thakur, R. K. (2015). Tool wear in turning ceramic reinforced aluminum matrix composites-A review. Journal of Composite Materials, 49(24), 2949-2961.

Kilıckap, E., Cakır, O., Aksoy, M., \& Inan, A. (2005). Study of tool wear and surface roughness in machining of homogenised SiC-p reinforced aluminium metal matrix composite. Journal of Materials Processing Technology, 164, 862-867.

Kumar, A., Mahapatra, M. M., \& Jha, P. K. (2014). Effect of machining parameters on cutting force and surface roughness of in situ $\mathrm{Al}-4.5 \% \mathrm{Cu} / \mathrm{TiC}$ metal matrix composites. Measurement, 48, 325-332.

Manna, A., \& Bhattacharayya, B. (2003). A study on machinability of Al/SiC-MMC. Journal of Materials Processing Technology, 140(1), 711-716.

Mishra, P., Das, D., Ukamanal, M., Routara, B., \& Sahoo, A. (2015). Multi-response optimization of process parameters using Taguchi method and grey relational analysis during turning AA 7075/SiC composite in dry and spray cooling environments. International Journal of Industrial Engineering Computations, 6(4), 445-456.

Panda, S. R., Senapati, A. K., \& Mishra, P. C. (2017). Multi-regression prediction model for surface roughness and tool wear in turning novel aluminum alloy (LM6)/fly ash composite using response surface and central composite design methodology Pages. International Journal of Industrial Engineering Computations, 8(1), 1-18.

Ramezani, M. (2015). Surface roughness prediction of particulate composites using artificial neural networks in turning operation. Decision Science Letters, 4(3), 419-424.

Routara, B. C., Mohanty, S. D., Datta, S., Bandyopadhyay, A., \& Mahapatra, S. S. (2010). Combined quality loss (CQL) concept in WPCA-based Taguchi philosophy for optimization of multiple surface quality characteristics of UNS C34000 brass in cylindrical grinding. The International Journal of Advanced Manufacturing Technology, 51(1), 135-143.

Sahoo, A. K., \& Pradhan, S. (2013). Modeling and optimization of Al/SiCp MMC machining using Taguchi approach. Measurement, 46(9), 3064-3072.

Sahoo, A., Orra, K., \& Routra, B. (2013). Application of response surface methodology on investigating flank wear in machining hardened steel using PVD TiN coated mixed ceramic insert. International Journal of Industrial Engineering Computations, 4(4), 469-478.

Sahu, S. K., Mishra, P. C., Orra, K., \& Sahoo, A. K. (2015). Performance assessment in hard turning of AISI 1015 steel under spray impingement cooling and dry environment. Proceedings of the Institution of Mechanical Engineers, Part B: Journal of Engineering Manufacture, 229(2), 251-265.

Sahoo, A., Rout, A., \& Das, D. (2015). Response surface and artificial neural network prediction model and optimization for surface roughness in machining. International Journal of Industrial Engineering Computations, 6(2), 229-240.

Sahoo, P., Pratap, A., \& Bandyopadhyay, A. (2017). Modeling and optimization of surface roughness and tool vibration in CNC turning of Aluminum alloy using hybrid RSM-WPCA methodology. International Journal of Industrial Engineering Computations, 8(3), 385-398.

Yanming, Q., \& Zehua, Z. (2000). Tool wear and its mechanism for cutting SiC particle-reinforced aluminium matrix composites. Journal of materials processing technology, 100(1), 194-199.

Yang, Y., \& Li, J. F. (2010). Study on mechanism of chip formation during high-speed milling of alloy cast iron. The International Journal of Advanced Manufacturing Technology, 46(1), 43-50.

Yingfei, G., Jiuhua, X., \& Hui, Y. (2010). Diamond tools wear and their applicability when ultraprecision turning of $\mathrm{SiC} \mathrm{p/2009A1} \mathrm{matrix} \mathrm{composite.} \mathrm{Wear,} \mathrm{269(11),} \mathrm{699-708.}$

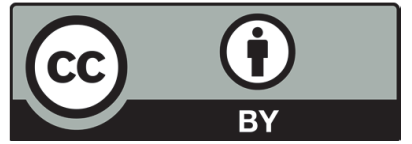

C 2018 by the authors; licensee Growing Science, Canada. This is an open access article distributed under the terms and conditions of the Creative Commons Attribution (CCBY) license (http://creativecommons.org/licenses/by/4.0/). 